\title{
Editorial
}

\section{Sequential Therapy for Hepatocellular Carcinoma after Failure of Atezolizumab plus Bevacizumab Combination Therapy}

\author{
Masatoshi Kudo \\ Department of Gastroenterology and Hepatology, Kindai University Faculty of Medicine, Osaka, Japan
}

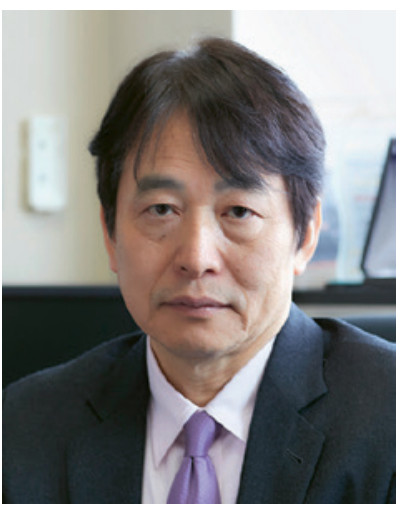

Prof. M. Kudo

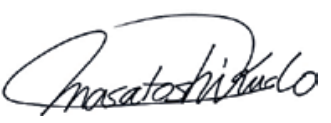

Editor Liver Cancer

\section{Keywords}

Hepatocellular carcinoma . Atezolizumab plus

bevacizumab · Lenvatinib · Regorafenib · Ramucirumab

\section{Introduction}

The combination of atezolizumab plus bevacizumab has demonstrated marked superiority to sorafenib, the current standard of care for unresectable hepatocellular carcinoma (HCC), with respect to overall survival (OS), progression-free survival (PFS), quality of life, and adverse events $[1,2]$. This will undoubtedly lead to atezolizumab plus bevacizumab combination therapy becoming

karger@karger.com www.karger.com/lic

Karger

GOPEN ACCESS
(C) 2021 The Author(s)

Published by S. Karger AG, Basel

This is an Open Access article licensed under the Creative Commons Attribution-NonCommercial-4.0 International License (CC BY-NC) (http://www.karger.com/Services/OpenAccessLicense), applicable to the online version of the article only. Usage and distribution for commercial purposes requires written permission. the first-line therapy of choice from the Fall of 2020. Regarding second-line and later therapies, it is expected, at least theoretically, that current first-line treatments will become second-line treatments, current second-line treatments will become third-line treatments, and so forth [3,4] (Fig. 1). Because atezolizumab and bevacizumab are antibodies, and their combination is unlikely to affect liver function, it is expected that $70-80 \%$ of patients who have started first-line therapy with atezolizumab plus bevacizumab will be eligible for second-line therapy. Thus, the choice of second-line therapy after atezolizumab plus bevacizumab is critical. This Editorial discusses the choice of sequential therapy after failure of atezolizumab plus bevacizumab combination therapy.

\section{Additional Effects of Molecular-Targeted Agents after Immune Checkpoint Inhibitor Therapy}

Administration of the anti-PD-1 antibody nivolumab to patients with non-small cell lung cancer results in sustained binding (for about 20 weeks) of nivolumab to PD-1 on lymphocytes [5]. Thus, it is also expected that programmed death-ligand 1 (PD-L1) antibody binding to PD-L1 on cancer cells is sustainable. This suggests that administration of a molecular-targeted agent that inhibits vascular endothelial growth factor (VEGF) as a subsequent therapy for patients with progressive disease treat- 


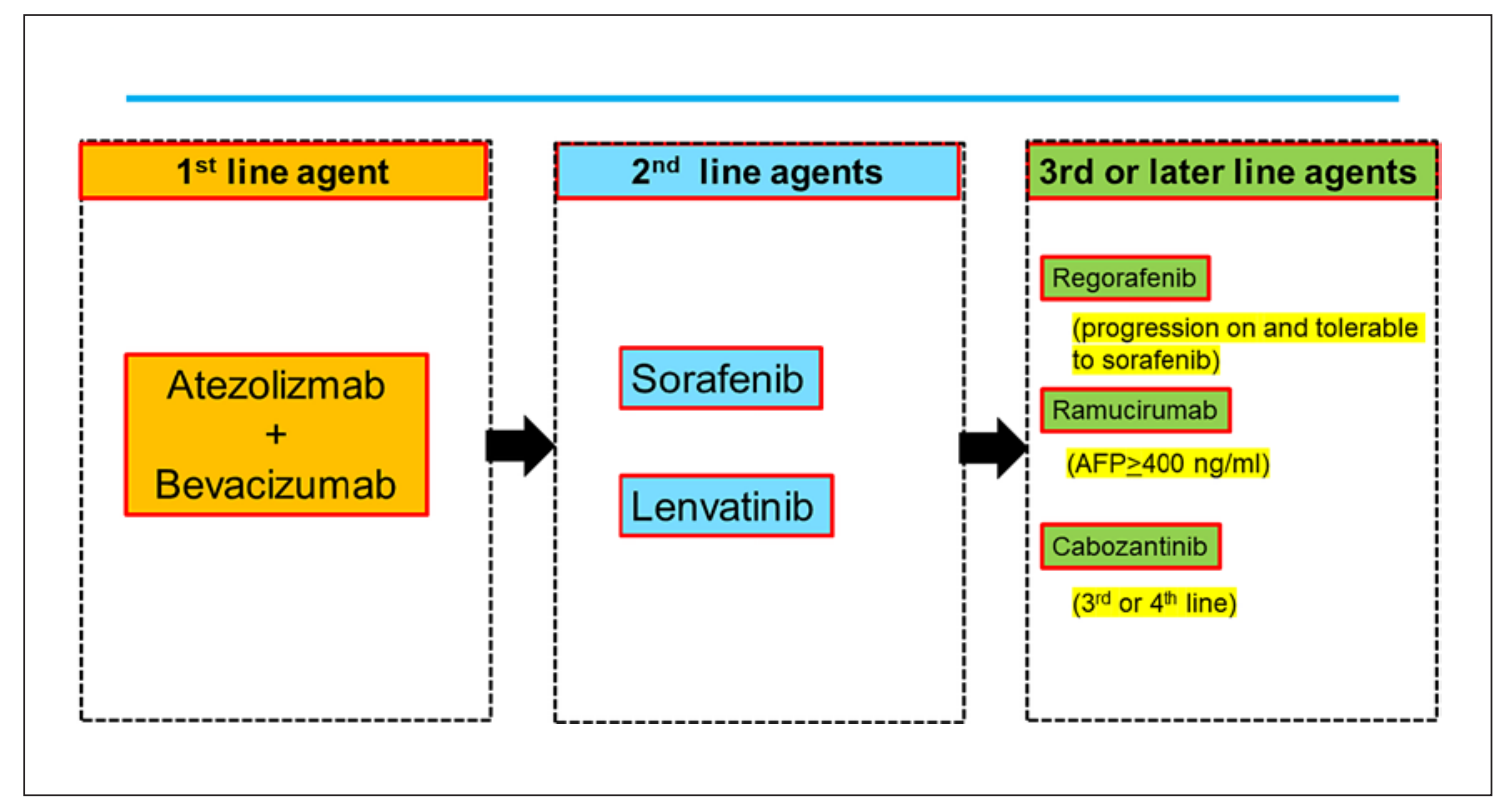

Fig. 1. Systemic therapy for advanced HCC: 2020 and beyond. HCC, hepatocellular carcinoma.

ed with atezolizumab plus bevacizumab may have synergistic effects similar to those of an immune checkpoint inhibitor (ICI) combined with a molecular-targeted agent $[6,7]$. Molecular-targeted agents with multi-kinase inhibitory activity, such as lenvatinib, regorafenib, ramucirumab and cabozantinib, are thought to have higher antitumor and tumor-necrosis activity than bevacizumab, which inhibits only a single VEGF-A ligand; thus, they are likely to induce release of more cancer antigens, keep the cancer immunity cycle going, and maintain the effects of remaining any anti-PD-L1 antibodies. Sorafenib (lowdose), lenvatinib, regorafenib, and cabozantinib improve the immune microenvironment by themselves (Fig. 2) [8-13]. Therefore, these molecular-targeted agents may be more effective when administered during the so-called golden time (i.e., the several months during which antiPD-1/PD-L1 antibody binding is sustained after ICI failure). This is consistent with the feeling that many physicians routinely have during clinical trials or real-world use of anti-PD-1/PD-L1 antibodies, that is, that molecular-targeted agents are more effective when administered after disease progression on ICI therapy. Aoki et al. [14] reported that lenvatinib showed extremely favorable results when used after failure of PD-1/PD-L1 antibody therapy even though it was used as 2nd-, 3rd-, or 4th-line treatment. The objective response rate (ORR) was $55.6 \%$, disease control rate was $86.1 \%$, PFS was 10 months, and median OS was 15.8 months. Particularly, median OS from the 1st-line treatment was 29.8 months which is much longer than 1st-line lenvatinib (13.6 months) [15] or 1st-line nivolumab (16.4 months) [16] (Table 1). Moreover, as demonstrated by Harding et al. [17], the effects of molecular-targeted agents are independent of WNT/ $\beta$-catenin-activating mutations, which means theoretically that these drugs are effective in primary-resistant cases in which ICI was ineffective due to WNT/ $\beta$-catenin-activating mutations (Fig. 3).

\section{Potential of Lenvatinib as a Second-Line Treatment after Failure of Atezolizumab plus Bevacizumab}

The current expectation is that sorafenib and lenvatinib, the first-line treatments before the advent of atezolizumab plus bevacizumab, will become second-line treatments and that regorafenib, cabozantinib, and ramucirumab will become third-line treatments (Fig. 1). WNT/ $\beta$-catenin mutations, which activate $\beta$-catenin, are found in approximately $20-30 \%$ of all HCCs. The immune classification of HCCs categorizes $\mathrm{WNT} / \beta$-catenin mutations into the immune exclusion or immune cold subclasses (Fig. 3) [18-20]. As with other carcinomas (e.g., renal, bladder, and ovarian), HCCs with elevated $\beta$-catenin protein levels also show less intratumoral T-cell 


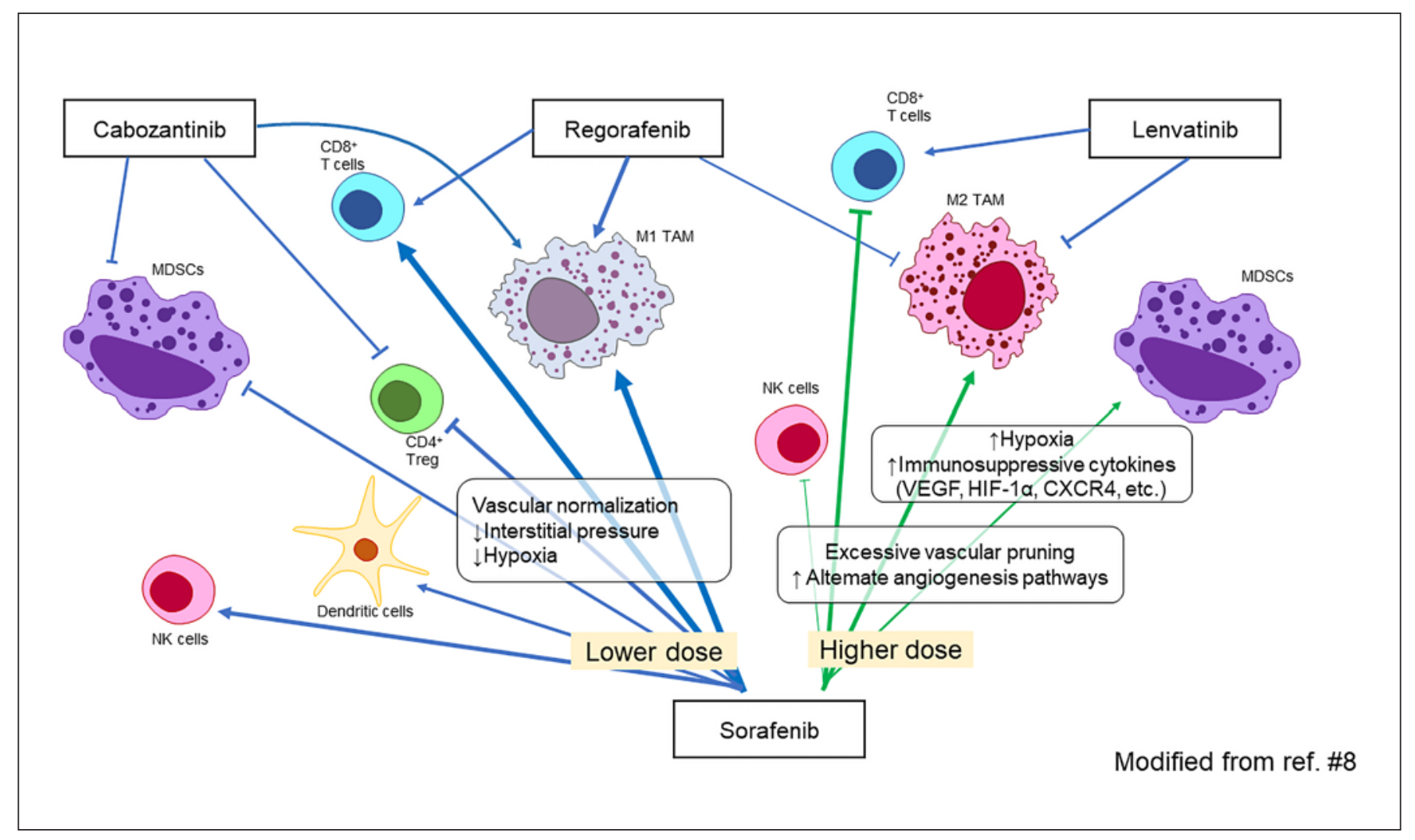

Fig. 2. Effect of molecular-targeted agents on the tumor immune microenvironment.

infiltration [21]. However, FGFR4 expression is higher in the population of tumors with $\mathrm{WNT} / \beta$-catenin-activating mutations, and there is a positive correlation between $\beta$-catenin mutations and FGFR4 expression [22]. It is well known that lenvatinib has a potent inhibitory effect on FGFR4 [23] (Table 2). Yamauchi et al. [22] conducted a study of 40 patients with HCC and reported that lenvatinib achieved a high response rate $(81 \%)$ in tumors with high expression of FGFR4, which is clearly higher than the corresponding rate in tumors without FGFR4 expression $(31 \%)$ (Table 3$)$. In addition, treatment with lenvatinib resulted in longer PFS in patients with high FGFR4 expression than in those without FGFR4 expression (5.5 vs. 2.7 months, respectively), indicating that lenvatinib shows higher antitumor activity against tumors with high FGFR4 expression (i.e., tumors with WNT/ $\beta$-catenin-activating mutations) (Table 3 ). Thus, even in patients who do not respond well to previous treatment with atezolizumab plus bevacizumab due to $\beta$-cateninactivating mutations, subsequent treatment with lenvatinib would still provide better results due to potent in- hibitory effect on FGFR4 [24]. In fact, as stated earlier in an ICI trial conducted at our hospital, lenvatinib demonstrated extremely high efficacy in patients who had progressed on previous therapy with a PD-1/PD-L1 checkpoint inhibitor [14]. Specifically, lenvatinib following failure of PD-1/PD-L1 improved PFS (10 months) OS (15.8 months) (from the start of lenvatinib), ORR (55.6\%), and disease control rate (86.1\%) [14] (Table 1). OS since initiation of ICI therapy was 29.8 months [14] (Table 1), which is much longer than that conferred by lenvatinib alone as first-line therapy [15].

\section{Potential of Sorafenib and Regorafenib as Second- Line Treatments after Failure of Atezolizumab plus Bevacizumab}

As noted above, sorafenib, lenvatinib, regorafenib, ramucirumab and cabozantinib alter the immune microenvironment favorably on their own [8]. In particular, sorafenib at low doses improves the immune microenvi- 
Table 1. Comparison of efficacy and safety of lenvatinib after PD-1/PD-L1 antibody and REFLECT, CheckMate 459, and IMbrave 150 trials

\begin{tabular}{|c|c|c|c|c|}
\hline Study name & Aoki et al. [14] & REFLECT [15] & CheckMate 459 [16] & IMbrave 150 [1] \\
\hline Treatment & Sequential therapy & Monotherapy & Monotherapy & $\begin{array}{l}\text { Combination } \\
\text { therapy }\end{array}$ \\
\hline Agents & $\begin{array}{l}\text { Lenvatinib after PD-1/PD-L1 } \\
\text { antibody }\end{array}$ & Lenvatinib & $\begin{array}{l}\text { Nivolumab (subsequent } \\
\text { therapy } 51 \% \text { ) }\end{array}$ & $\begin{array}{l}\text { Atezolizumab plus } \\
\text { bevacizumab }\end{array}$ \\
\hline Study design & Retrospective (proof of concept) & Phase III & Phase III & Phase III \\
\hline Treatment line & 2-4th line & 1st line & 1st line & 1st line \\
\hline \multicolumn{5}{|l|}{ Efficacy } \\
\hline ORR (RECISTv1.1), \% & 22.2 & 18.8 per IIR & 15.0 & 27.3 \\
\hline ORR (mRECIST), \% & 55.6 & 40.6 per IIR & NA & 33.2 \\
\hline Median OS from 1st-line initiation, months & 29.8 & 13.6 & 16.4 & $\mathrm{NE}$ \\
\hline Adverse events, $\%$ & $\begin{array}{l}\text { HT } 44 \\
\text { Diarrhea } 42 \\
\text { Appetite loss } 42 \\
\text { Fatigue } 36 \\
\text { AST increase } 58 \\
\text { Any grade } 100 \\
\text { Grade 3-4 56 }\end{array}$ & $\begin{array}{l}\text { HT } 42 \\
\text { Diarrhea } 39 \\
\text { Appetite loss } 34 \\
\text { BW loss } 31 \\
\text { AST increase } 14 \\
\text { Any grade } 99 \\
\text { Grade 3-4 } 75\end{array}$ & $\begin{array}{l}\text { Fatigue } 11 \\
\text { Pruritus } 11 \\
\text { Rash } 11 \\
\text { AST increase } 11 \\
\text { Appetite loss } 6 \\
\text { NA } \\
\text { Grade 3-4 } 22 \text { (TRAE) }\end{array}$ & $\begin{array}{l}\text { HT } 30 \\
\text { Diarrhea } 19 \\
\text { Fatigue } 20 \\
\text { AST increase } 20 \\
\text { Any grade } 98 \\
\text { Grade 3-4 } 57\end{array}$ \\
\hline
\end{tabular}

ORR, objective response rate; DCR, disease control rate; PFS, progression-free survival; OS, overall survival; HT, hypertension; IIR, independent imaging review; NA, not available; NE, not evaluable; TRAE, treatment-related adverse event.

Table 2. Comparison of kinase inhibitory effect on targeted molecule between lenvatinib and sorafenib

\begin{tabular}{lll}
\hline & \multicolumn{2}{l}{$\mathrm{IC}_{50}, \mathrm{nmol} / \mathrm{L}$} \\
\cline { 2 - 3 } & lenvatinib & sorafenib \\
\hline VEGFR-1 & $\mathbf{4 . 7}$ & $\mathbf{2 1}$ \\
VEGFR-2 & $\mathbf{3}$ & $\mathbf{2 1}$ \\
VEGFR-3 & 2.3 & $\mathbf{1 6}$ \\
FGFR1 & $\mathbf{6 1}$ & $\mathbf{3 4 0}$ \\
FGFR2 & $\mathbf{2 7}$ & $\mathbf{1 5 0}$ \\
FGFR3 & $\mathbf{5 2}$ & $\mathbf{3 4 0}$ \\
FGFR4 & $\mathbf{4 3}$ & $\mathbf{3 , 4 0 0}$ \\
PDGFRa & $\mathbf{2 9}$ & $\mathbf{1 . 6}$ \\
PDGFR $\beta$ & $\mathbf{1 6 0}$ & $\mathbf{2 7}$ \\
RAF1 & $\mathbf{1 , 6 1 0}$ & $\mathbf{4 6 . 4}$ \\
BRAF & $\mathbf{8 , 6 6 0}$ & $\mathbf{3 1 4}$ \\
\hline
\end{tabular}

VEGF, vascular endothelial growth factor. Bold character represents an inhibitory effect on each molecule. Modified from ref. [24].
Table 3. Efficacy of lenvatinib on FGFR4 positive HCC $(n=40)$

\begin{tabular}{lll}
\hline & $\begin{array}{l}\text { FGFR4-ICH } \\
\text { positive, } n=27\end{array}$ & $\begin{array}{l}\text { FGFR4-IHC } \\
\text { negative, } n=13\end{array}$ \\
\hline $\mathrm{CR}, n$ & 0 & 0 \\
$\mathrm{PR}, n$ & 22 & 4 \\
$\mathrm{SD}, n$ & 3 & 4 \\
$\mathrm{PD}, n$ & 2 & 5 \\
ORR, \% & 81 & 31 \\
DCR, \% & 93 & 62 \\
PFS, months & 5.5 & 2.5 \\
\hline
\end{tabular}

IHC, immunohistochemical staining; CR, complete response; $\mathrm{PR}$, partial response; $\mathrm{SD}$, stable disease; $\mathrm{PD}$, progressive disease; ORR, objective response rate; DCR, disease control rate; PFS, progression-free survival; HCC, hepatocellular carcinoma. Modified from ref. [22]. 


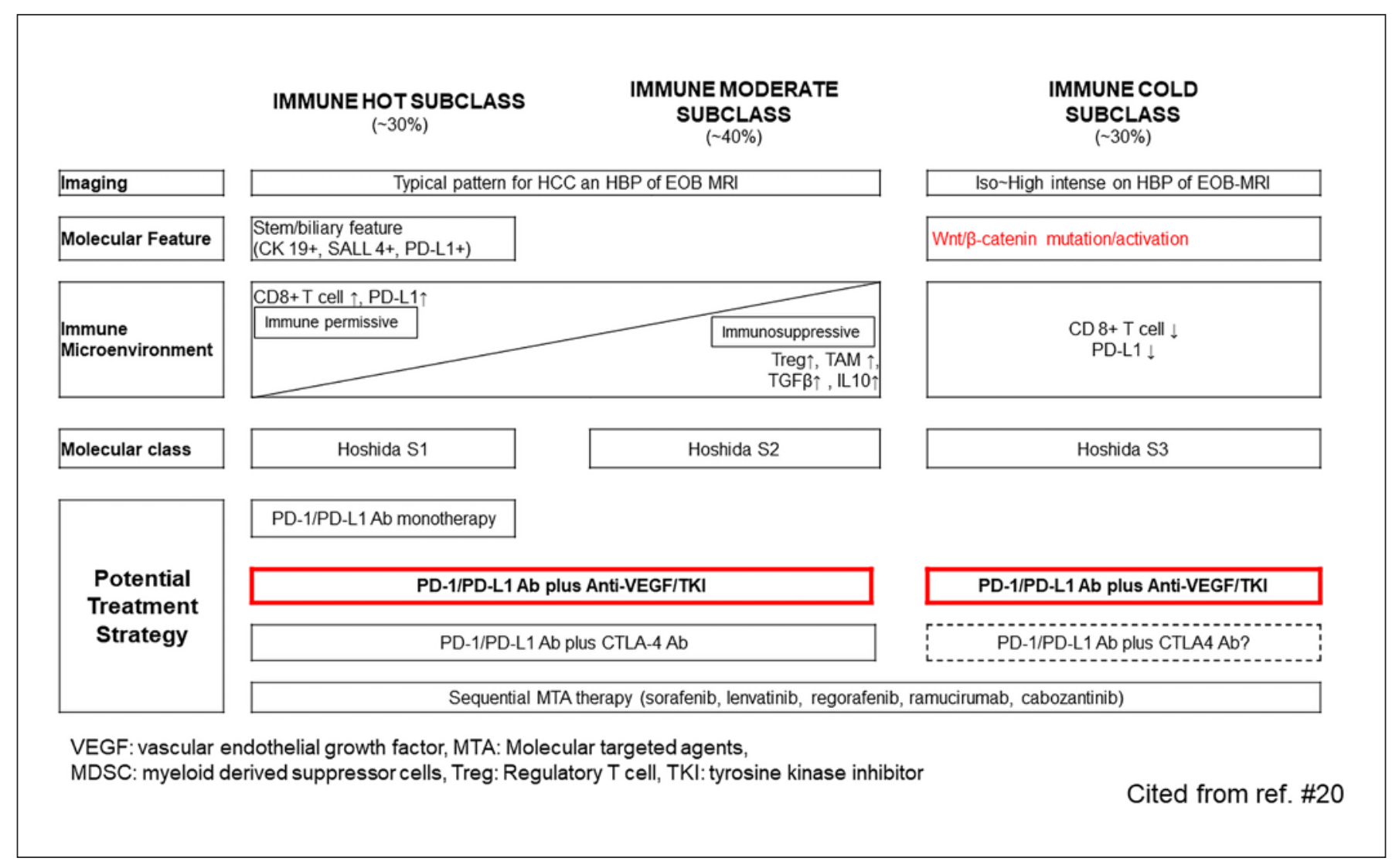

Fig. 3. Immunological classification and possible treatment strategies. VEGF, vascular endothelial growth factor; HCC, hepatocellular carcinoma; MDSC, myeloid-derived suppressor cell.

ronment as revealed in a systemic review of the in vivo and in vitro study [25] that lower dose of sorafenib is associated with beneficial immunomodulatory effect, such as increasing the M1 polarization of tumor-associated macrophages (TAMs) $[26,27]$ enhancing $\mathrm{CD}^{+} \mathrm{T}$-cell infiltration and function [28-30] suppressing regulatory $\mathrm{T}$ cell numbers [31-33] or reversing the function of myeloid-derived suppressor cells in the tumor microenvironment $[8,9$, 25] (Fig. 2). On the other hand, it is suggested that higher dose of sorafenib has immunosuppressive effect through induction of hypoxia and recruitment of myeloid-derived suppressor cells, TAM, or other suppressive cells $[8,11-13,25,34-37]$ (Fig. 2). Regorafenib also suppresses TAMs, induces M1 macrophage activation, and increases CD8-positive cell numbers [8]. Meanwhile, osteopontin induces TAMs via colony-stimulating factor-1 (CSF-1), thereby exerting a suppressive regulatory effect on the tumor immune microenvironment and inhibiting infiltration of CD8-positive cells into the tumor [38]. Experimental study of both CSF-1 receptor (CSF-1R) inhibitors and anti-PD-L1 antibodies to tumors leads to significantly higher numbers of CD8-positive and CD4-positive cells, and significantly lower numbers of TAMs, than in controls [38]. These observations suggest that inhibiting CSF-1R suppresses tumor infiltration by TAMs, thereby enhancing PD-L1 inhibition [38]. Thus, as shown in Figure 4, CSF-1R inhibitors should theoretically increase intratumoral infiltration of CD8positive and CD4-positive cells by inhibiting TAMs and M2 macrophages, and exert a potent antitumor effect when combined with anti-PD-1/PD-L1 antibodies.

Moreover, increased TAM infiltration plays an important role in acquired resistance to anti-VEGF therapy. Therefore, it is assumed that use of CSF-1R inhibitors in patients that have acquired resistance will allow tumor cells to regain sensitivity to anti-VEGF therapy (Fig. 5) [39]. Thus, CSF-1R inhibitors may be effective in patients that do not respond to atezolizumab plus bevaci- 
a OPN driving immunosuppressive microenvironment

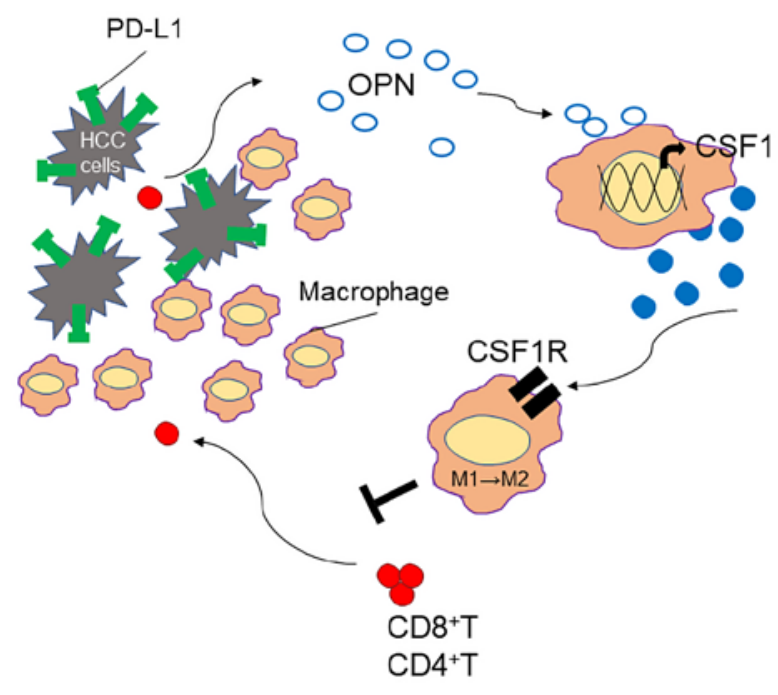

OPN, osteopontin; CSF-1R, colony-stimulating factor-1 b CSF1R inhibitor and anti-PD-L1 combination decreases TAM infiltration and increases intratumoural T cells activation.

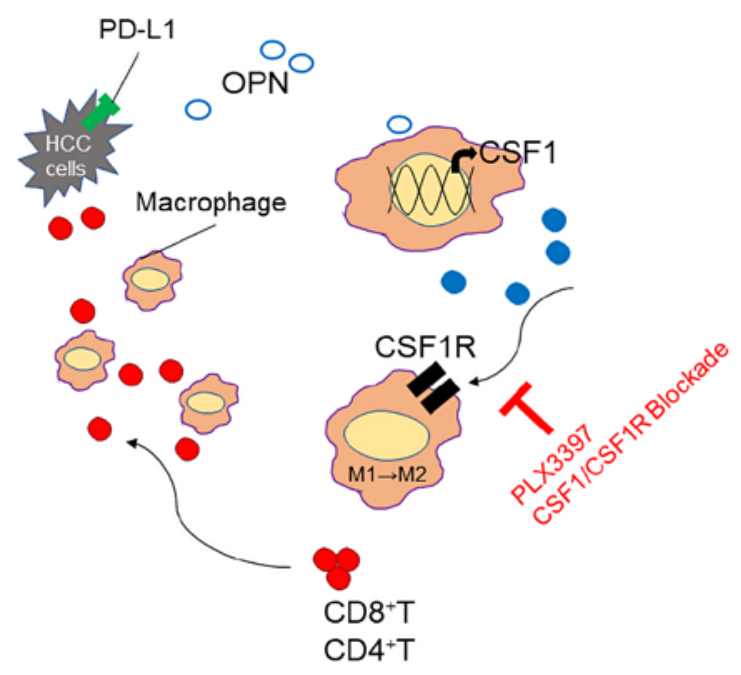

Fig. 4. CSF-1R inhibitors change tumor microenvironment from immune suppressive of immune responsive. CSF-1R, colony stimulating factor 1 receptor; TAM, tumor-associated macrophage. Modified from ref. [38].

Table 4. Pharmacological inhibitory kinase activity of regorafenib and its metabolites

\begin{tabular}{llrc}
\hline Gene symbol & \multicolumn{2}{l}{$K_{\mathrm{d}}, \mathrm{nmol} / \mathrm{L}$} & \\
\cline { 2 - 4 } & regorafenib $^{*}$ & $\mathrm{M}-2$ & $\mathrm{M}-5$ \\
\hline VEGFR-2 & $57 / 28$ & 29 & 31 \\
PDGFRA & $21 / 19$ & 7.3 & 11 \\
PDGFRB & $19 / 8.3$ & 11 & 11 \\
KIT & $35 / 6.9$ & 9.8 & 5.8 \\
RET & $7.7 / 5.2$ & 7.6 & 5.8 \\
CSF1R & $43 / 10$ & 21 & 13 \\
FLT3 & $9.6 / 4.8$ & 6.7 & 2.6 \\
RAF1 & $87 / 59$ & 130 & 66 \\
BRAF & $42 / 52$ & 24 & 17 \\
\hline
\end{tabular}

M-2, M-5: metabolites of regorafenib. * Duplicate $\mathrm{K}_{\mathrm{d}}$ values are given. zumab due to resistance to bevacizumab. In fact, regorafenib suppresses CSF-1R through its kinase activity (Table 4) [40]; thus, it may be effective at improving the immunosuppressive microenvironment. The wellknown effects of regorafenib include (1) inhibiting angiogenesis in the vascular endothelium; (2) inhibiting cancer extension; (3) inhibiting metastatic activity; and (4) inhibiting CSF-1R, which in turn strengthens immunity [40-45]. Studies in a mouse model of HCC show that low-dose regorafenib induces activated CD8-positive cells while at the same time significantly reducing the number of TAMs; it also decreases M2 macrophage numbers while significantly increasing those of M1 macrophages [46]. These results suggest that regorafenib significantly alters the immune microenvironment, changing it from suppressive to responsive. Therefore, regorafenib, which has such a promising effect, may also be effective as a second-line treatment when administered at low doses after failure of atezolizumab plus bevacizumab, particularly for HCCs that have progressed due to resistance to bevacizumab. 


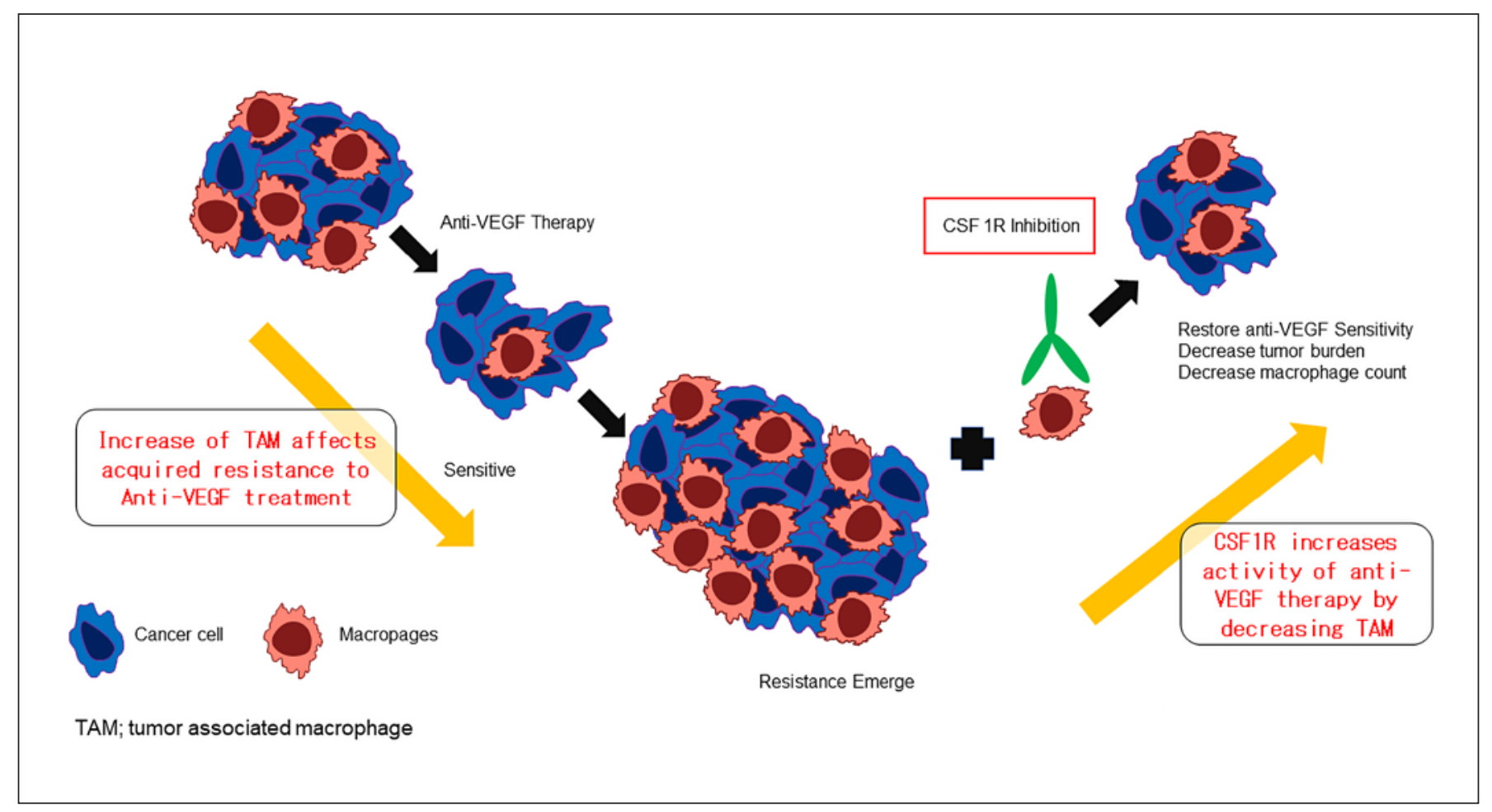

Fig. 5. Effect of CSF1R inhibitor on acquired resistance to anti-VEGF therapy for cancer. VEGF, vascular endothelial growth factor. Modified from ref. [39].

\section{Potential of Other Molecular-Targeted Agents as Subsequent Therapy after Failure of Atezolizumab plus Bevacizumab}

As mentioned above, binding of anti-PD-1 antibodies to PD-1 on lymphocytes and of anti-PD-L1 antibodies to PD-L1 on cancer cells is expected to last for more than 20 weeks [5]. Therefore, in general terms, molecular-targeted agents as second-line treatment after failure of PD-1/ PD-L1 antibodies are considered to be as effective as combination therapy with ICIs plus anti-VEGF/moleculartargeted agents. Moreover, if the effect of anti-PD-L1 antibodies lasts for several months, then sequential therapy with agents with antitumor activity stronger than that of bevacizumab (i.e., lenvatinib, sorafenib, regorafenib, ramucirumab and cabozantinib) would be more effective.

Furthermore, and from a different perspective, ramucirumab may be a candidate for second-line therapy when serum AFP level is $\geq 400 \mathrm{ng} / \mathrm{mL}$. Since ramucirumab does not impair liver function and quality of life [47, 48], its use as a second-line treatment after atezolizumab plus bevacizumab may offer patients a better quality of life, with fewer adverse events, while maintaining stable dis- ease even in elderly patients. Furthermore, recent report by Finn et al. [49] showed that ramucirumab achieved ORR of $16.7 \%$ (4 of 24 cases) in patients who failed prior PD-1/PD-L1 antibody therapies (nivolumab in 3 and durvalumab plus tremelimumab in 1) in the REACH-2 Open-Label Expansion Cohort, suggesting that ramucirumab may be effective after ICI therapy. Therefore, there may be cases in which it is appropriate to give this drug as a "short break" (e.g., in elderly patients and patients with poor PS). In any case, the efficacy of these drugs as second-line treatments after failure of atezolizumab plus bevacizumab therapy should be evaluated in real-world clinical practice.

\section{Conclusion}

The current expectation is that sorafenib and lenvatinib, both first-line treatments before the advent of atezolizumab plus bevacizumab [1,50], will become second-line treatments and that regorafenib, cabozantinib, and ramucirumab will become third-line treatments (Fig. 1). At present, lenvatinib is likely to be the most fa- 
vorable second-line treatment and is theoretically expected to provide a higher response rate, longer PFS and OS than other targeted agents since its effectiveness on FGFR4 overexpressed (WNT/ $\beta$-catenin mutated) HCC. Actually, in our study, lenvatinib treatment after failure of PD-1/ PD-L1 antibody therapy provided much better outcomes than lenvatinib alone or nivolumab alone as the first-line therapy [14] (Table 1). For third-line and later therapies, a variety of agents will be used in a variety of sequences.

However, as mentioned above, regorafenib [51], cabozantinib [52], and ramucirumab $[53,54]$ were proved to prolong overall survival by clinical trials; thus, they may be used as second-line treatments after atezolizumab plus bevacizumab in some cases. In light of this, the question of which sequence is best will have to be addressed in real-world clinical settings. Through such studies, it will be increasingly important to clarify the actual status of sequential therapy use after failure of atezolizumab plus bevacizumab combination therapy.

\section{Statement of Ethics}

The authors have no ethical conflicts to disclose.

\section{Conflict of Interest Statement}

Lectures: Eisai, Bayer, Chugai and MSD; grants: EA Pharma, Eisai, Gilead, Takeda, Otsuka, Eli Lilly, Chugai, and Taiho; advisory consulting: Eisai, Ono, MSD, Eli Lilly, Roche, Takeda, and BMS. Masatoshi Kudo is Editor-in-Chief of Liver Cancer.

\section{Funding Sources}

The authors did not receive any funding.

\section{Author Contributions}

M. Kudo conceived, wrote, and approved the final manuscript.

\section{References}

1 Finn RS, Qin S, Ikeda M, Galle PR, Ducreux M, Kim T-Y, et al. Atezolizumab plus bevacizumab in unresectable hepatocellular carcinoma. N Engl J Med. 2020;382(20):1894905.

2 Kudo M. A new era in systemic therapy for hepatocellular carcinoma: atezolizumab plus bevacizumab combination therapy. Liver Cancer. 2020;9(2):119-37.

3 Bouattour M, Mehta N, He AR, Cohen EI, Nault JC. Systemic treatment for advanced hepatocellular carcinoma. Liver Cancer. 2019;8(5):341-58.

4 Rimassa L, Pressiani T, Merle P. Systemic treatment options in hepatocellular carcinoma. Liver Cancer. 2019;8(6):427-46.

5 Osa A, Uenami T, Koyama S, Fujimoto K, Okuzaki D, Takimoto T, et al. Clinical implications of monitoring nivolumab immunokinetics in non-small cell lung cancer patients. JCI Insight. 2018;3(19):e59125.

6 Kudo M. Immuno-oncology therapy for hepatocellular carcinoma: current status and ongoing trials. Liver Cancer. 2019;8(4):22138.

7 Finn RS, Ikeda M, Zhu AX, Sung MW, Baron $\mathrm{AD}$, Kudo M, et al. Phase Ib study of lenvatinib plus pembrolizumab in patients with unresectable hepatocellular carcinoma. J Clin Oncol. 2020;38(26):2960-70.

8 Cheng AL, Hsu C, Chan SL, Choo SP, Kudo M. Challenges of combination therapy with immune checkpoint inhibitors for hepatocellular carcinoma. J Hepatol. 2020;72(2):307-19.

9 Chang CJ, Yang YH, Chiu CJ, Lu LC, Liao CC, Liang CW, et al. Targeting tumor-infiltrating Ly6G(+) myeloid cells improves sorafenib ef- ficacy in mouse orthotopic hepatocellular carcinoma. Int J Cancer. 2018;142:1878-89.

10 Patnaik A, Swanson KD, Csizmadia E, Solanki A, Landon-Brace N, Gehring MP, et al. Cabozantinib eradicates advanced murine prostate cancer by activating antitumor innate immunity. Cancer Discov. 2017;7(7): 750-65.

11 Lin YY, Tan CT, Chen CW, Ou DL, Cheng AL, Hsu C. Immunomodulatory effects of current targeted therapies on hepatocellular carcinoma: implication for the future of immunotherapy. Semin Liver Dis. 2018;38(4): 379-88.

12 Zhang W, Zhu XD, Sun HC, Xiong YQ, Zhuang PY, Xu HX, et al. Depletion of tumorassociated macrophages enhances the effect of sorafenib in metastatic liver cancer models by antimetastatic and antiangiogenic effects. Clin Cancer Res. 2010;16(13):3420-30.

13 Yao W, Ba Q, Li X, Li H, Zhang S, Yuan Y, et al. A natural CCR2 antagonist relieves tumorassociated macrophage-mediated immunosuppression to produce a therapeutic effect for liver cancer. EBioMedicine. 2017;22:58-67.

14 Aoki T, Kudo M, Ueshima K, Morita M, Chishina $\mathrm{H}$, Takita $\mathrm{M}$, et al. Exploratory analysis of lenvatinib therapy in patients with unresectable hepatocellular carcinoma who have failed prior PD-1/PD-L1 checkpoint blockade. Cancers. 2020;12(10):3048.

15 Kudo M, Finn RS, Qin S, Han K-H, Ikeda K, Piscaglia F, et al. Lenvatinib versus sorafenib in first-line treatment of patients with unresectable hepatocellular carcinoma: a randomised phase 3 non-inferiority trial. Lancet. 2018;391(10126):1163-73.
16 Yau T, Park JW, Finn RS, Cheng AL, Mathurin P, Edeline J, et al. CheckMate 459: a randomized, multi-center phase III study of nivolum$\mathrm{ab}$ vs sorafenib as first-line treatment in $\mathrm{pa}$ tients with advanced hepatocellular carcinoma. Ann Oncol. 2019;30(Suppl 5):v874-5.

17 Harding JJ, Nandakumar S, Armenia J, Khalil DN, Albano M, Ly M, et al. Prospective genotyping of hepatocellular carcinoma: clinical implications of next-generation sequencing for matching patients to targeted and immune therapies. Clin Cancer Res. 2019;25(7): 2116-26.

18 Llovet JM, Montal R, Sia D, Finn RS. Molecular therapies and precision medicine for hepatocellular carcinoma. Nat Rev Clin Oncol. 2018;15(10):599-616.

19 Pinyol R, Sia D, Llovet JM. Immune exclusion-Wnt/CTNNB1 class predicts resistance to immunotherapies in HCC. Clin Cancer Res. 2019;25(7):2021-3.

20 Kudo M. Gd-EOB-DTPA-MRI could predict $\mathrm{WNT} / \beta$-catenin mutation and resistance to immune checkpoint inhibitor therapy in hepatocellular carcinoma. Liver Cancer. 2020; 9(5):479-90.

21 Luke JJ, Bao R, Sweis RF, Spranger S, Gajewski TF. WNT/ $\beta$-catenin pathway activation correlates with immune exclusion across human cancers. Clin Cancer Res. 2019;25(10): 3074-83.

22 Yamauchi M, Ono A, Ishikawa A, Kodama K, Uchikawa S, Hatooka H, et al. Tumor fibroblast growth factor receptor 4 level predicts the efficacy of lenvatinib in patients with advanced hepatocellular carcinoma. Clin Transl Gastroenterol. 2020;11(5):e00179. 
23 Tohyama O, Matsui J, Kodama K, Hata-Sugi N, Kimura T, Okamoto K, et al. Antitumor activity of lenvatinib (e7080): an angiogenesis inhibitor that targets multiple receptor tyrosine kinases in preclinical human thyroid cancer models. J Thyroid Res. 2014;2014:638747.

24 Deng H, Kan A, Lyu N, Mu L, Han Y, Liu L, et al. Dual vascular endothelial growth factor receptor and fibroblast growth factor receptor inhibition elicits antitumor immunity and enhances programmed cell death-1 checkpoint blockade in hepatocellular carcinoma. Liver Cancer. 2020;9(3):338-57.

25 Heine A, Schilling J, Grünwald B, Krüger A, Gevensleben H, Held SA, et al. The induction of human myeloid derived suppressor cells through hepatic stellate cells is dose-dependently inhibited by the tyrosine kinase inhibitors nilotinib, dasatinib and sorafenib, but not sunitinib. Cancer Immunol Immunother. 2016;65:273-82.

26 Sprinzl MF, Reisinger F, Puschnik A, Ringelhan $\mathrm{M}$, Ackermann K, Hartmann D, et al. Sorafenib perpetuates cellular anticancer effector functions by modulating the crosstalk between macrophages and natural killer cells. Hepatology. 2013;57(6):2358-68.

27 Wei X, Tang C, Lu X, Liu R, Zhou M, He D, et al. MiR-101 targets DUSP1 to regulate the TGF- $\beta$ secretion in sorafenib inhibits macrophage-induced growth of hepatocarcinoma. Oncotarget. 2015;6(21):18389-405.

28 Romero AI, Chaput N, Poirier-Colame V, Rusakiewicz S, Jacquelot N, Chaba K, et al. Regulation of CD4(+)NKG2D(+) Th1 cells in patients with metastatic melanoma treated with sorafenib: role of IL-15R $\alpha$ and NKG2D triggering. Cancer Res. 2014;74:68-80.

29 Sunay MM, Foote JB, Leatherman JM, Edwards JP, Armstrong TD, Nirschl CJ, et al. Sorafenib combined with HER-2 targeted vaccination can promote effective $\mathrm{T}$ cell immunity in vivo. Int Immunopharmacol. 2017;46:112-23.

30 Chuang HY, Chang YF, Liu RS, Hwang JJ. Serial low doses of sorafenib enhance therapeutic efficacy of adoptive $\mathrm{T}$ cell therapy in a murine model by improving tumor microenvironment. PloS one. 2014;9(10):e109992.

31 Chen ML, Yan BS, Lu WC, Chen MH, Yu SL, Yang PC, et al. Sorafenib relieves cell-intrinsic and cell-extrinsic inhibitions of effector $\mathrm{T}$ cells in tumor microenvironment to augment antitumor immunity. Int J Cancer. 2014; 134(2):319-31.

32 Cao M, Xu Y, Youn JI, Cabrera R, Zhang X, Gabrilovich D, et al. Kinase inhibitor Sorafenib modulates immunosuppressive cell populations in a murine liver cancer model. Lab Invest. 2011;91(4):598-608.
33 Cabrera R, Ararat M, Xu Y, Brusko T, Wasserfall C, Atkinson MA, et al. Immune modulation of effector $\mathrm{CD} 4+$ and regulatory $\mathrm{T}$ cell function by sorafenib in patients with hepatocellular carcinoma. Cancer Immunol Immunother. 2013;62(4):737-46.

34 Lam W, Jiang Z, Guan F, Huang X, Hu R, Wang J, et al. PHY906(KD018), an adjuvant based on a 1800-year-old Chinese medicine, enhanced the anti-tumor activity of Sorafenib by changing the tumor microenvironment. Sci Rep. 2015;5:9384.

35 Chen Y, Liu YC, Sung YC, Ramjiawan RR, Lin TT, Chang CC, et al. Overcoming sorafenib evasion in hepatocellular carcinoma using CXCR4-targeted nanoparticles to co-deliver MEK-inhibitors. Sci Rep. 2017;7:44123.

36 Liu JY, Chiang T, Liu CH, Chern GG, Lin TT, Gao DY, et al. Delivery of siRNA Using CXCR4-targeted nanoparticles modulates tumor microenvironment and achieves a potent antitumor response in liver cancer. Mol Ther. 2015;23(11):1772-82.

37 Zhou SL, Zhou ZJ, Hu ZQ, Huang XW, Wang $\mathrm{Z}$, Chen EB, et al. Tumor-associated neutrophils recruit macrophages and T-regulatory cells to promote progression of hepatocellular carcinoma and resistance to sorafenib. Gastroenterology. 2016;150(7):1646-e17.

38 Zhu Y, Yang J, Xu D, Gao XM, Zhang Z, Hsu JL, et al. Disruption of tumour-associated macrophage trafficking by the osteopontininduced colony-stimulating factor-1 signalling sensitises hepatocellular carcinoma to anti-PD-L1 blockade. Gut. 2019;68(9):165366.

39 Lyons YA, Pradeep S, Wu SY, Haemmerle M, Hansen JM, Wagner MJ, et al. Macrophage depletion through colony stimulating factor 1 receptor pathway blockade overcomes adaptive resistance to anti-VEGF therapy. Oncotarget. 2017;8(57):96496-505.

40 Zopf D, Fichtner I, Bhargava A, Steinke W, Thierauch KH, Diefenbach K, et al. Pharmacologic activity and pharmacokinetics of metabolites of regorafenib in preclinical models. Cancer Med. 2016;5(11):3176-85.

41 Abou-Elkacem L, Arns S, Brix G, Gremse F, Zopf D, Kiessling F, et al. Regorafenib inhibits growth, angiogenesis, and metastasis in a highly aggressive, orthotopic colon cancer model. Mol Cancer Ther. 2013;12(7):132231.

42 Matsushime H, Roussel MF, Ashmun RA, Sherr CJ. Colony-stimulating factor 1 regulates novel cyclins during the G1 phase of the cell cycle. Cell. 1991;65(4):701-13.

43 Wilhelm SM, Dumas J, Adnane L, Lynch M, Carter CA, Schütz G, et al. Regorafenib (BAY 73-4506): a new oral multikinase inhibitor of angiogenic, stromal and oncogenic receptor tyrosine kinases with potent preclinical antitumor activity. Int J Cancer. 2011;129(1):245-55.
44 Schmieder R, Hoffmann J, Becker M, Bhargava A, Müller T, Kahmann N, et al. Regorafenib (BAY 73-4506): antitumor and antimetastatic activities in preclinical models of colorectal cancer. Int J Cancer. 2014;135(6): 1487-96.

45 Takigawa H, Kitadai Y, Shinagawa K, Yuge R, Higashi Y, Tanaka S, et al. Multikinase inhibitor regorafenib inhibits the growth and metastasis of colon cancer with abundant stroma. Cancer Sci. 2016;107(5):601-8.

46 Chen C-W, Ou D-L, Hsu C-L, Lin L, Cheng A-L, Hsu C. FRI-471-Regorafenib may enhance efficacy of anti-program cell death-1 therapy in hepatocellular carcinoma through modulation of macrophage polarization. J Hepatol. 2019;70(1):e605-6.

47 Kudo M, Galle PR, Llovet JM, Finn RS, Vogel A, Motomura K, et al. Ramucirumab in elderly patients with hepatocellular carcinoma and elevated alpha-fetoprotein after sorafenib in REACH and REACH-2. Liver Int. 2020;40(8): 2008-20.

48 Kudo M, Galle P, Brandi G, Kang YK, Yen CJ, Finn RS, et al. Effect of ramucirumab or best supportive care on ALBI grade in patients with advanced HCC: Results from REACH and REACH-2. JHEP Rep. 2020;3(2):100215.

49 Finn RS, de Toni EN, Yau T, Yen CJ, Hsu CH, Chan SL, et al. Ramucirumab for patients with advanced hepatocellular carcinoma and elevated alpha fetoprotein following a nonsorafenib based systemic therapy: interim results from an expansion cohort of the phase 3 REACH-2 study. ILCA. 2020.

50 Lee MS, Ryoo BY, Hsu CH, Numata K, Stein $\mathrm{S}$, Verret W, et al. Atezolizumab with or without bevacizumab in unresectable hepatocellular carcinoma (GO30140): an open-label, multicentre, phase $1 \mathrm{~b}$ study. Lancet Oncol. 2020;21(6):808-20.

51 Bruix J, Qin S, Merle P, Granito A, Huang YH, Bodoky G, et al. Regorafenib for patients with hepatocellular carcinoma who progressed on sorafenib treatment (RESORCE): a randomised, double-blind, placebo-controlled, phase 3 trial. Lancet. 2017;389(10064):56-66.

52 Abou-Alfa GK, Meyer T, Cheng AL, ElKhoueiry AB, Rimassa L, Ryoo BY, et al. Cabozantinib in patients with advanced and progressing hepatocellular carcinoma. $\mathrm{N}$ Engl J Med. 2018;379(1):54-63.

53 Kudo M. Better efficacy of ramucirumab in Japanese patients than in the global population with unresectable hepatocellular carcinoma. Liver cancer. 2020;9(3):232-44.

54 Zhu AX, Kang YK, Yen CJ, Finn RS, Galle PR, Llovet JM, et al. Ramucirumab after sorafenib in patients with advanced hepatocellular carcinoma and increased alpha-fetoprotein concentrations (REACH-2): a randomised, double-blind, placebo-controlled, phase 3 trial. Lancet Oncol. 2019;20:282-96. 